\title{
Lajes alveolares pré-fabricadas: estudo da influência do número e do instante de preenchimento de alvéolos no ganho de resistência à força cortante
}

\section{Precast hollow core slabs: the influence of the instances and quantity of filled cores on shear strength gain}

Gregory Lee Pinheiro ${ }^{1}$, Roberto Chust Carvalho ${ }^{2}$, Fernando Menezes de Almeida Filho ${ }^{2}$

\footnotetext{
${ }^{1}$ Programa de Pós-graduação em Estruturas e Construção Civil - PPGECiv, Deciv/UFSCar, Rod. Washington Luis, km 235 - São Carlos, SP CEP:13565-905. e-mail: gregoryleepinheiro@gmail.com

2 e-mail: chust@ufscar.br; almeidafilho@ufscar.br
}

\section{RESUMO}

Este trabalho aborda a influência do momento e número de alvéolos preenchidos no ganho de resistência à força cortante em lajes alveolares pré-fabricadas, por meio de um estudo teórico que faz uso das equações contidas na ABNT NBR 14861-2011 para o cálculo da resistência ao esforço cortante, e por um estudo experimental onde foram ensaiadas lajes sem alvéolos preenchidos, e com o preenchimento de 2 ou 4 alvéolos antes ou após a liberação da protensão na pista de concretagem. O estudo teórico aponta a vantagem da execução do preenchimento após a liberação da protensão, convergindo aos valores experimentais para lajes com 4 alvéolos preenchidos, porém diverge para o caso de preenchimento de 2 alvéolos.

Palavras-chave: Lajes alveolares, preenchimento de alvéolos, resistência ao esforço cortante, concreto préfabricado.

\section{ABSTRACT}

This paper discusses the influence of instances and quantity of filled cores on shear strength gain of pretensioned precast concrete hollow core slabs, by means of a theoretical study that uses the available equations given by ABNT NBR 14861 [3] for shear strength calculation, and an experimental study where slabs without core filing, with 02 or 04 cores filled before or after the release of the strands prestressing in the casting bed, were tested under shear strength. The theoretical study confirms the advantage of the core filling execution after the release of prestressing, converging from experimental study when 04 cores were filled and diverging from this when 04 cores were filled.

Keywords: Hollow core slab, core filling, shear strength, precast concrete.

\section{INTRODUÇÃO}

As lajes alveolares pré-fabricadas protendidas (LAPs) podem ser definidas como o elemento de concreto protendido com vazios contínuos. Estes elementos apresentam-se como uma solução estrutural avançada para piso e forro, possuindo montagem rápida e custo competitivo em virtude do melhor uso dos materiais. A sua seção de altura reduzida contribui para a diminuição do peso próprio e torna a estrutura mais eficiente, conforme STANTON [20].

Por meio de um processo de fabricação industrial, aliado a uma geometria com vazios contínuos e a técnica da protensão, as LAPs podem alcançar grandes vãos e suportar carregamentos elevados.

Segundo PALMER e SCHULTZ [17], os vazios gerados pelos alvéolos ao longo da laje não interferem significativamente na resistência a flexão do elemento, justificando assim sua seção transversal.

De modo geral a produção das lajes alveolares ocorre por dois processos de produção: por extrusão, 
onde um concreto de abatimento reduzido é forçado por um equipamento de extrusão, sendo os alvéolos formados por um conjunto de roscas infinitas que compactam e empurram o concreto ao redor de tubos; por moldagem, onde um concreto de abatimento reduzido, contudo superior ao utilizado no processo por extrusão, é moldado e compactado por meio de um conjunto de formas fixas e móveis, em camadas sucessivas ao longo do equipamento.

Devido ao seu processo produtivo, as LAPs não possuem armadura transversal, logo, a resistência ao esforço cortante está diretamente relacionada a geometria do alvéolo, traço de concreto e processo de produção.

É comum que o engenheiro de estruturas se depare com a situação onde a LAP resiste aos esforços de flexão, entretanto, não suportam os esforços cortantes. Como solução pode-se adotar o preenchimento de alvéolos na região das extremidades da laje, tornando maior a área de concreto e consequentemente a capacidade resistente à força cortante.

Neste trabalho se investiga através de um estudo teórico, baseado nas equações da ABNT NBR 14861 [3], e de um estudo experimental, desenvolvido com lajes produzidas por extrusão, os efeitos do preenchimento de alvéolos bem como a influência do instante de preenchimento no ganho de resistência ao esforço cortante.

\subsection{Resistência ao esforço cortante}

No Brasil a análise da resistência de lajes alveolares em regiões próximas ao apoio é feita por meio da ABNT NBR 14861 [3], onde a verificação à força cortante deve ser feita na seção transversal mais crítica ao longo do vão do elemento, a partir da distância de 0,5 da altura da extremidade do seu apoio.

É previsto por esta norma que a resistência deve ser considerada satisfatória quando atender as condições:

$$
\begin{aligned}
& V_{S d} \leq V_{R d 1} \\
& V_{S d} \leq V_{R d 2} \text { ou } V_{S d} \leq V_{R d 2, \text { capa }}
\end{aligned}
$$

Sendo:

$\mathrm{V}_{\mathrm{Sd}}$ : força cortante solicitante de cálculo na seção;

$\mathrm{V}_{\mathrm{Rd} 1}$ : força cortante resistente de cálculo na seção;

$\mathrm{V}_{\mathrm{Rd} 2}$ : força cortante resistente de cálculo na seção para as diagonais comprimidas de concreto;

$\mathrm{V}_{\mathrm{Rd2capa}}$ : força cortante resistente de cálculo na seção, das diagonais comprimidas de concreto da laje alveolar com capa estrutural de concreto e alvéolos preenchidos.

A Figura 1 mostra o esquema da seção transversal da laje alveolar com as dimensões consideradas para o cálculo e o preenchimento de alvéolos.

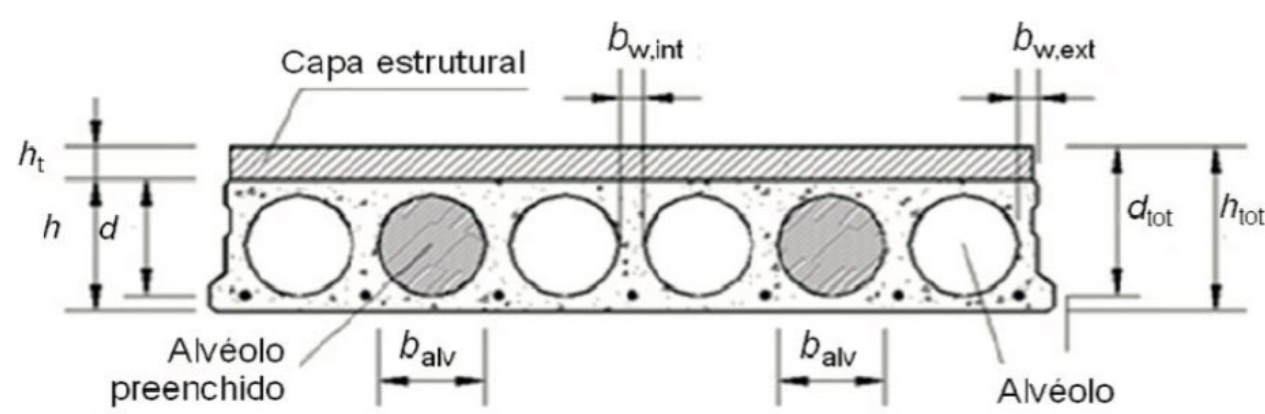

Figura 1: Seção transversal de laje alveolar com dimensões consideradas para cálculo e preenchimento de alvéolo (ABNT NBR $14861[3])$.

O valor da resistência ao esforço cortante de lajes com ou sem capa estrutural é obtido por: 


$$
\begin{aligned}
& V_{R d 2}=\frac{1}{2} \cdot v \cdot f_{c d} \cdot 0,9 \cdot d \cdot \Sigma b_{w, 1} \\
& V_{R d 2, \text { capa }}=\frac{1}{2} \cdot v \cdot f_{c d} \cdot 0,9 \cdot d_{t o t} \cdot \Sigma b_{w, 2} \\
& v=0,7-\frac{f_{c k}}{200} \geq 0,5
\end{aligned}
$$

Sendo:

$\Sigma_{\mathrm{bw}, 1} \mathrm{e} \Sigma_{\mathrm{bw}, 2}$ : somatório das nervuras (internas e externas) da laje alveolar e da parcela da seção com alvéolos, respectivamente;

d: $\quad$ altura útil da seção transversal da laje alveolar;

$\mathrm{d}_{\text {tot: }}$ : altura útil da seção transversal da laje alveolar mais capa estrutural;

$\mathrm{f}_{\text {cd: }}$ resistência de cálculo à compressão do concreto.

A ABNT NBR 14861 [3] prevê o aumento da resistência à força cortante em lajes alveolares por meio do preenchimento dos alvéolos. Quando este procedimento for adotado, seu comprimento longitudinal ao longo dos alvéolos deve ser pelo menos maior que $\mathrm{L}_{\mathrm{pr}}$.

$$
L_{p r}=L_{p t 2}+L_{f c}
$$

\section{Sendo:}

$\mathrm{L}_{\mathrm{pt2}}$ : valor superior de projeto para o comprimento de transmissão;

$\mathrm{L}_{\mathrm{fc}}$ : soma do comprimento necessário para atender as solicitações de força cortante com altura da seção transversal.

A resistência à força cortante das lajes alveolares, numa determinada seção transversal, deve ser calculada por meio da expressão:

$$
V_{R d}=\left[\tau_{R d} \cdot k \cdot\left(1,2+40 \cdot \rho_{t}\right)+0,15 \cdot \sigma_{c p}\right\rfloor b_{w} \cdot d
$$

Sendo:

$\mathrm{V}_{\mathrm{rd}}: 0,25 \cdot \mathrm{f}_{\mathrm{ctd}}$;

$\mathrm{k}: 1,6-\mathrm{d} \geq 1$, com $\mathrm{d}$ em metros.

Sendo:

$\mathrm{f}_{\text {ctd: }}$ resistência à tração de projeto do concreto;

$\rho_{1}$ : taxa de armadura específica para a seção da laje alveolar pré-moldada;

$\sigma_{\mathrm{cp}}$ : tensão de compressão do concreto devido à força de protensão de projeto para o caso da laje sem alvéolo preenchido;

$\mathrm{b}_{\mathrm{w}}$ : largura das nervuras internas e externas da laje alveolar;

d: $\quad$ altura útil da seção transversal.

\subsubsection{Resistência à força cortante de lajes alveolares com alvéolos preenchidos antes da liberação da protensão}

Um dos casos possíveis de se executar o preenchimento dos alvéolos é no instante após a concretagem da laje alveolar, ou seja, fazer o preenchimento antes da liberação da protensão na pista, designado neste trabalho como Preenchimento na fábrica.

$$
V_{R d, a 1}=V_{c, 2}+V_{p, 2}
$$




$$
\begin{aligned}
& V_{c, 2}=0,25 \cdot f_{c t d} \cdot k \cdot\left(1,2+40 \cdot \rho_{2}\right) \cdot \Sigma b_{w, 2} \cdot d \\
& V_{p, 2}=0,15 \cdot \sigma_{c p, 2} \cdot \Sigma b_{w, 2} \cdot d
\end{aligned}
$$

Sendo:

$\rho_{2}$ : taxa de armadura específica para a seção da laje alveolar pré-moldada com o alvéolo preenchido;

$\sum_{\mathrm{bw}, 2}$ : somatório das espessuras das nervuras internas e externas da laje alveolar e parcela da seção com alvéolos preenchidos;

$$
\Sigma b_{w, 2}=\Sigma b_{w, 1}+0,5 \cdot b_{a l v} \cdot \frac{E c}{E p}
$$

$\sigma_{\mathrm{cp}, 2}$ : tensão de compressão do concreto devido à força de protensão de projeto para o caso da laje com alvéolo preenchido antes da liberação da protensão.

\subsubsection{Resistência à força cortante de lajes alveolares com alvéolos preenchidos após da liberação da protensão na pista}

A outra possibilidade de se executar o preenchimento dos alvéolos é após a liberação da protensão designado neste trabalho como Preenchimento na obra.

$$
\begin{aligned}
& V_{R d, a 2}=V_{c, 2}+V_{p, 1} \\
& V_{c, 2}=0,25 \cdot f_{c t d} \cdot k \cdot\left(1,2+40 \cdot \rho_{2}\right) \cdot \Sigma b_{w, 2} \cdot d \\
& V_{p, 1}=0,15 \cdot \sigma_{c p, 1} \cdot \Sigma b_{w, 1} \cdot d
\end{aligned}
$$

Sendo:

$\rho_{2}$ : taxa de armadura específica para a seção da laje alveolar pré-moldada com o alvéolo preenchido;

$\sum_{\mathrm{bw}, 1}$ : somatório das espessuras das nervuras internas e externas da laje alveolar sem a parcela da seção com alvéolos preenchidos;

$\sigma_{\mathrm{cp}, 1}$ : é a tensão de compressão do concreto devido à força de protensão de projeto para o caso da laje sem alvéolo preenchido antes da liberação da protensão.

\section{MATERIAIS E MÉTODOS}

\subsection{Estudo teórico}

O estudo teórico abordou o cálculo da resistência ao esforço cortante em laje alveolares por meio do uso das equações contidas na ABNT NBR 14861 [3], e apresentadas no item 1 desta pesquisa.

\subsection{Estudo experimental}

O estudo experimental foi desenvolvido por meio da realização de 9 ensaios de resistência à força cortante em lajes alveolares produzidas pelo processo de extrusão, possuindo altura de $200 \mathrm{~mm}$ e comprimento de $6000 \mathrm{~mm}$, concreto de $\mathrm{f}_{\mathrm{ck}}=35 \mathrm{MPa}$ e abatimento $0 \mathrm{~mm}$, e com uso de 7 cordoalhas de $12,7 \mathrm{~mm}$. As lajes foram projetadas e produzidas de modo a se aproximar das unidades abordadas no estudo teórico desta pesquisa.

Os elementos estudados foram monitorados desde o recebimento da sua matéria prima antes do início de sua fabricação até a fase final dos ensaios e análises. A fim de se garantir a uniformidade e confiabilidade dos ensaios, as amostras em estudo pertenceram ao mesmo lote e processo de fabricação, possuindo a mesma classe de concreto, tipo de cordoalha, dimensões, e processo de cura. Assegurou-se ainda que todas as amostras fossem ensaiadas sob as mesmas condições. 


\subsubsection{Produção das lajes alveolares}

Por se tratar de um processo industrial de fabricação, a produção das lajes alveolares pode ser apresentada em tópicos que seguem uma sequência usual de ocorrência das etapas, conforme:

I. Limpeza da pista de concretagem: a pista foi limpa de modo a eliminar qualquer tipo de resíduo sólido ou líquido que possa comprometer a qualidade visual e estrutural do elemento;

II. Posicionamento da armadura: os cabos de protensão usados na laje foram posicionados sobre a pista de concretagem de maneira conveniente, respeitando as indicações de projeto;

III. Protensão dos cabos: por meio de macacos hidráulicos, os cabos foram protendidos separadamente com uma determinada tensão de projeto;

IV. Ancoragem das cordoalhas: após a protensão, os cabos foram ancorados na cabeceira da pista de concretagem por meio de cunhas, a fim de manter a protensão na armadura $(*)$;

V. Aplicação do desmoldante: o produto foi aplicado na pista de concretagem, na interface pista-laje, de modo a garantir a qualidade da laje alveolar após a produção no instante da desforma;

VI. Extrusão: o equipamento de fabricação de lajes por extrusão foi alimentado com concreto, e a produção do elemento se deu de maneira ininterrupta ao longo da pista $(* *)$.

VII. Preenchimento de alvéolos: para o caso de lajes com alvéolos preenchidos, os mesmos foram abertos em suas extremidades com o concreto ainda fresco, com o uso de uma haste de madeira;

VIII. Cura: após o término das etapas iniciais de produção e execução de aberturas nas lajes, elas passaram pelo processo de cura a vapor; $(* * *)$;

IX. Liberação: ao final do processo de cura, a laje que foi produzida como uma peça única, necessitou ser cortada e transportada ao local de armazenamento. Para determinar se o tempo do processo de cura do concreto havia sido o suficiente, corpos de prova de concreto foram ensaiados pelo laboratório da fábrica para a liberação da pista.

X. Desprotensão: com a pista liberada pelo laboratório, foi realizado o procedimento de desprotensão da pista de concretagem, com o intuito de transferir ao elemento concretado as tensões de protensão, permitindo assim a execução dos cortes das lajes em dimensões convenientes.

XI. Corte transversais: estes cortes foram realizados com o concreto já curado e com a pista desprotendida, por meio de uma serra que se desloca sobre os trilhos da pista de concretagem.

XII. Transporte: como etapa final da produção das lajes, estas foram transportadas e armazenadas na fábrica em um local protegido de intempéries, para aguardar o período total de cura de 28 dias.

(*) Nas lajes alveolares pré-fabricadas protendiadas é utilizada a pré-tração, pois a armadura é tracionada antes do lançamento do concreto e a protensão se dá por meio da aderência entre o concreto (após endurecimento) e os cabos.

(**) O processo consiste em alimentar o equipamento de fabricação por extrusão com concreto de baixo abatimento, que é empurrado para a pista por um sistema de rosca sem fim.

(***) Segundo EL DEBS [12] o processo de cura é indicado para acelerar o procedimento de liberação da protensão da pista e permitir uma nova etapa de produção.

\subsubsection{Processo de preenchimento de alvéolos}

A ABNT NBR 14861 [3] indica que para o preenchimento dos alvéolos, deve ser usado concreto adequado, com mesma resistência e durabilidade do concreto do elemento a ser preenchido.

A seção pode ser considerada como única, ou seja, há um comportamento conjunto entre a capa estrutural, a seção de projeto e a área dos alvéolos preenchidos, desde que seja garantida a aderência entre a capa estrutural e a superfície da laje alveolar, bem como entre o concreto lançado no alvéolo e a superfície do alvéolo da laje alveolar. Dessa forma, o preenchimento dos alvéolos influencia nas considerações de cálculo.

É necessário garantir o completo preenchimento dos alvéolos, havendo controle da retração do concreto, para que não ocorram efeitos desfavoráveis para a aderência entre a laje e o concreto lançado nos alvéolos.

Segundo a norma o preenchimento dos alvéolos pode ocorrer tanto anteriormente à liberação da protensão, ou seja, logo após a extrusão ou moldagem da laje na pista de protensão (dependendo do processo de fabricação da laje) quanto posteriormente à liberação da protensão, na fábrica ou no local da obra.

A Figura 2 mostra o posicionamento recomendado por norma dos alvéolos preenchidos para o acrés- 
cimo da força cortante.
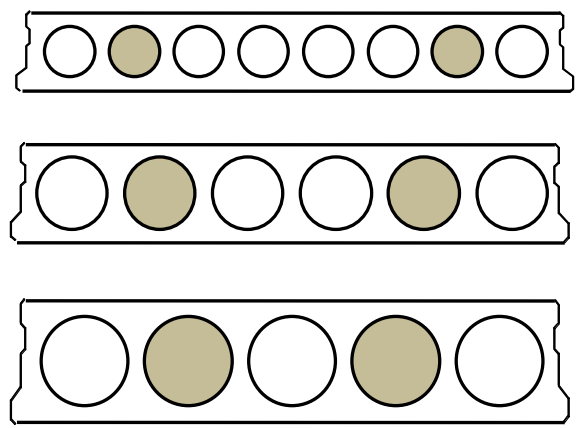

Figura 2: Posicionamento recomendado para o alvéolo preenchido (ABNT NBR 14861 [3]).

A ABNT NBR 14861 [3] trata do caso de lajes com dois alvéolos preenchidos, e caso esse número seja superior, como ocorre nesta pesquisa, é recomendado que se use evidência científica por meio de: normalização internacional ou validação experimental. Neste estudo foi feito uso de 2 e 4 alvéolos preenchidos, segundo o posicionamento mostrado pela Figura 3.

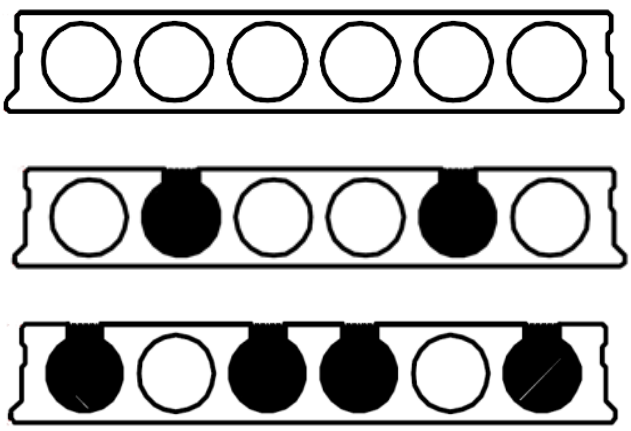

Figura 3: Posicionamento recomendado para o alvéolo preenchido segundo Pinheiro [18].

O preenchimento de alvéolos consistiu inicialmente em executar uma abertura na parte superior das lajes, por meio de uma régua de madeira, na região localizada entre as nervuras, visando proporcionar o acesso para o lançamento do concreto de preenchimento. O preenchimento foi realizado com um concreto de abatimento superior ao da laje $(150 \pm 20 \mathrm{~mm})$ e com duas resistências distintas, 35 ou $45 \mathrm{MPa}$. O procedimento de preenchimento é apresentado pela Figura 4.
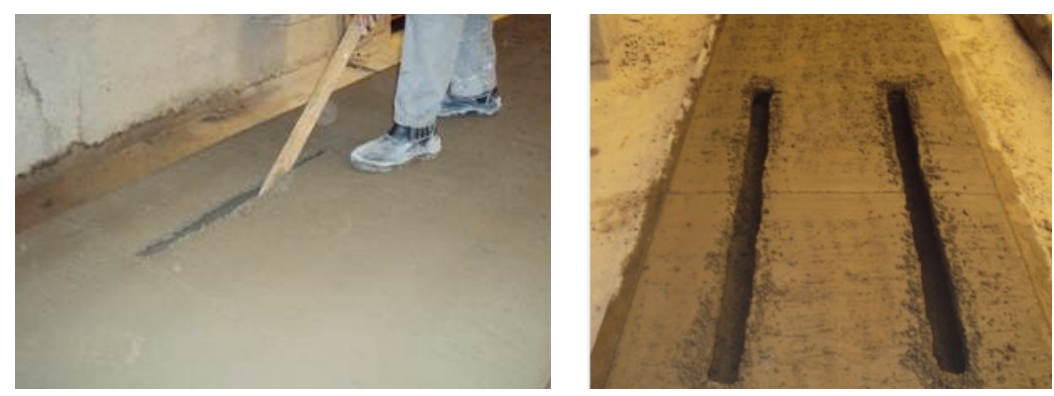

Figura 4: Abertura dos alvéolos segundo Pinheiro [18].

Após a abertura dos nichos, foi realizado o preenchimento dos alvéolos com o uso de um concreto de abatimento mais elevado, conforme a Figura 5. 

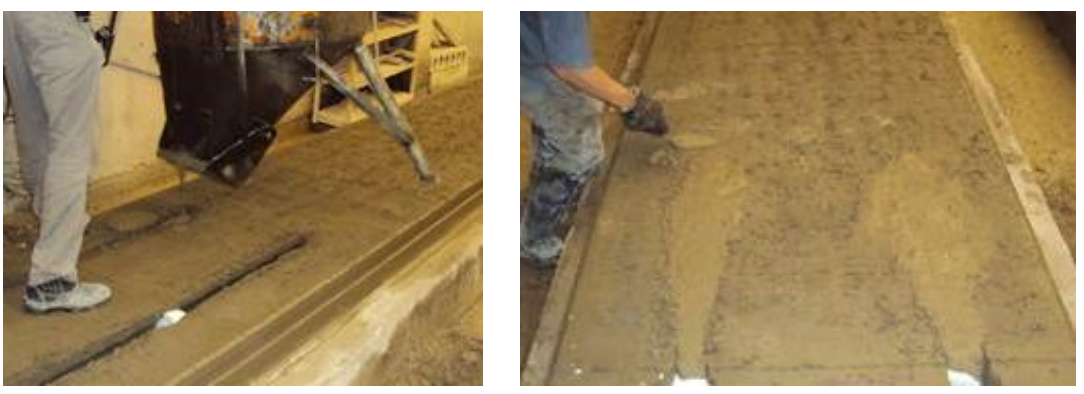

Figura 5: Preenchimento dos alvéolos segundo Pinheiro [18].

O preenchimento dos alvéolos foi realizado em dois momentos distintos:

i. Preenchimento com a pista de concretagem protendida, ou seja, anteriormente à liberação da protensão e imediatamente após a extrusão com o concreto da laje no estado fresco (Preenchimento na fábrica);

ii. Preenchimento com a pista de concretagem desprotendida, ou seja, após à liberação da protensão com o concreto da laje no estado endurecido (preenchimento na obra).

\subsubsection{Cura}

As lajes foram submetidas ao processo de cura térmica a vapor, especialmente indicada para acelerar o procedimento de liberação da protensão da pista de concretagem.

Ao final do processo de cura, as lajes foram armazenadas em um local coberto, sem a incidência de intempéries a fim de minimizar os efeitos de fluência e de retração, até que atingissem sua idade de 28 dias para o ensaio.

\subsubsection{Modelos ensaiados}

Os elementos ensaiados foram nomeados de modo a facilitar a sua identificação, sendo cada exemplar representado pela letra $\mathrm{L}$ acompanhada do número do modelo. Para a descrição do local de preenchimento (quando ocorrer), a letra $\mathrm{P}$ identifica que o preenchimento ocorre na fábrica, e a letra $\mathrm{O}$ preenchimento em obra, sendo estas acompanhas de um valor numérico que apresenta sua resistência. Por fim, a letra A seguida de um valor numérico expõe o número de alvéolos preenchidos.

Como exemplo tem-se: $\mathrm{L}_{2}-\mathrm{P}_{35}-\mathrm{A}_{2}$ que trata da laje de número 2, com dois alvéolos preenchidos antes da liberação da protensão na pista de concretagem por meio de um concreto de $\mathrm{f}_{\text {ck }}$ igual a $35 \mathrm{MPa}$.

\subsubsection{Execução dos ensaios}

Os ensaios foram executados em uma fábrica de elementos pré-fabricados localizada na região sul do país, e seguiu o método FIP [14], apresentado na Figura 6. 


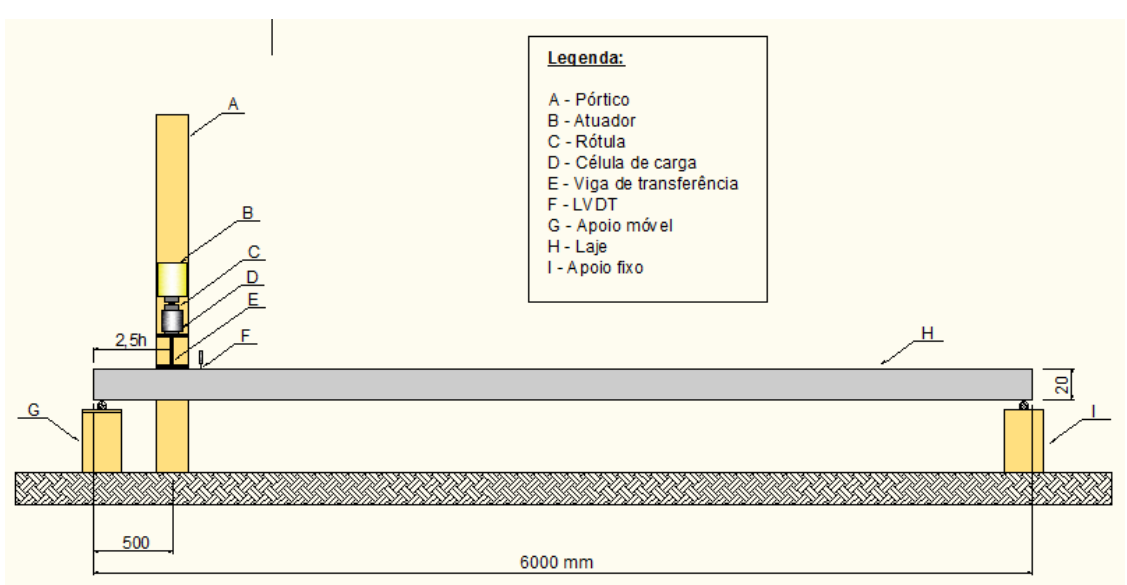

ELEVAÇÃO 1

Figura 6: Configuração dos ensaios segundo Pinheiro [18].

Os elementos ensaiados foram posicionados sobre dois apoios rígidos, elaborados de modo a propiciar a livre movimentação e rotação da laje, não influenciando no modelo bi-apoiado idealizado.

Após posicionar a laje, aplicou-se a cada ensaio uma fina camada de areia sob viga de transferência de carga do atuador para o elemento ensaiado, garantindo uma melhor distribuição do carregamento. Com a viga de transferência instalada, posicionou-se o pórtico de ensaio sobre a laje e executou-se a ligação da célula de carga e transdutores ao módulo de aquisição de dados, Figura 7:
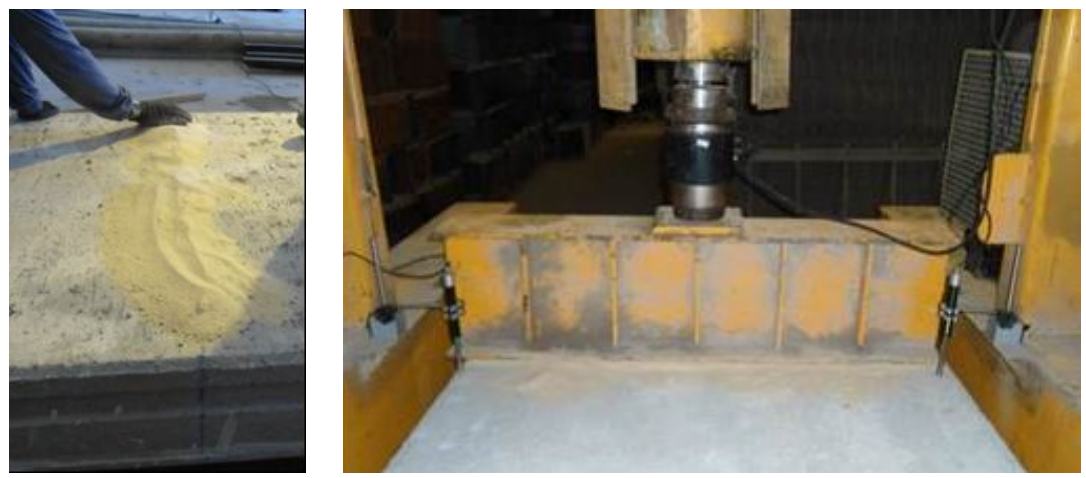

Figura 7: Preparação e execução do ensaio da laje segundo Pinheiro [18].

Todos os ensaios foram executados conforme o arranjo mostrado pela Figura 8 e seu comportamento se deu conforme o esperado quanto a deformação e ao modo de ruptura.
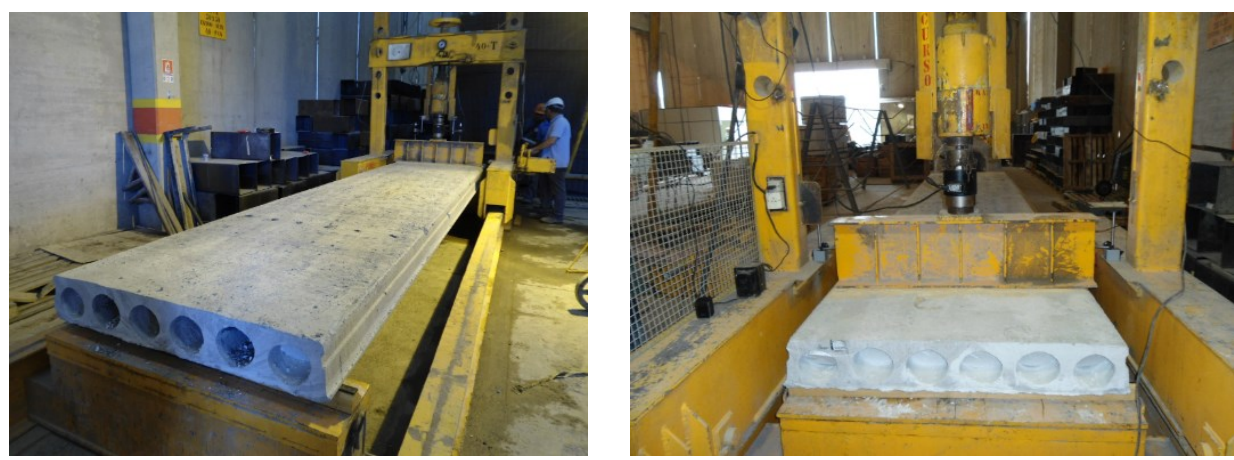

Figura 8: Configuração dos ensaios segundo Pinheiro [18]. 
Os valores máximos dos carregamentos das lajes foram coletados para a realização da análise dos ensaios.

\section{RESULTADOS E DISCUSSÃO}

A partir dos carregamentos obtidos nos ensaios realizados com as lajes, calculou-se os valores experimentais de resistência à forç̧a cortante $\left(\mathrm{V}_{\text {Rexp }}\right)$, e por meio das equações normativas apresentadas no item 1 , os valores teóricos característicos de resistência à força cortante $\left(\mathrm{V}_{\mathrm{RK}}\right)$, para lajes com alvéolos preenchidos antes da liberação da protensão na pista de concretagem, apresentados na Tabela 1.

Tabela 1: Valores teóricos característicos $\left(\mathrm{V}_{\mathrm{RK}}\right)$ e experimentais $\left(\mathrm{V}_{\mathrm{Rexp}}\right)$ de resistência ao esforço cortante para lajes com preenchimento em fábrica - antes da liberação da protensão da pista de concretagem.

\begin{tabular}{c|c|c|c|c|c|c|c|c|c|c}
\hline Modelo & $\begin{array}{c}\mathrm{N}^{{ }^{\circ} \mathrm{de}} \\
\text { alvéolos } \\
\text { preench. }\end{array}$ & $\begin{array}{c}\text { Local de } \\
\text { preench. }\end{array}$ & $\begin{array}{c}\mathrm{f}_{\text {ck-laje }} \\
(\mathrm{MPa})\end{array}$ & $\begin{array}{c}\mathrm{f}_{\mathrm{ck}-\mathrm{alv} .} \\
(\mathrm{MPa})\end{array}$ & $\begin{array}{c}\mathrm{E} \\
(\mathrm{GPa})\end{array}$ & $\begin{array}{c}\mathrm{V}_{\mathrm{c}} \\
(\mathrm{kN})\end{array}$ & $\begin{array}{c}\mathrm{V}_{\mathrm{p}} \\
(\mathrm{kN})\end{array}$ & $\mathrm{V}_{\mathrm{c}} / \mathrm{V}_{\mathrm{p}}$ & $\begin{array}{c}\mathrm{V}_{\mathrm{RK}} \\
(\mathrm{kN})\end{array}$ & $\begin{array}{c}\mathrm{V}_{\text {Rexp }} \\
(\mathrm{kN})\end{array}$ \\
\hline L1-A0 & 0 & 0 & 56,83 & 0 & 30,86 & 107,22 & 53,90 & 1,99 & 161,12 & 198,9 \\
\hline L2-P35-A2 & 2 & pista & 56,83 & 33,75 & 19,52 & 144,52 & 67,15 & 2,15 & 211,67 & 221,2 \\
\hline L4-P45-A2 & 2 & pista & 56,83 & 38,88 & 17,41 & 139,90 & 64,20 & 2,18 & 204,10 & 243,4 \\
\hline L6-P35-A4 & 4 & pista & 56,83 & 33,75 & 19,52 & 143,86 & 53,90 & 2,67 & 197,76 & 190,7 \\
\hline L8-P45-A4 & 4 & pista & 56,83 & 38,88 & 17,41 & 139,90 & 53,90 & 2,60 & 193,80 & 211,8 \\
\hline
\end{tabular}

Na Tabela 2 são apresentados os valores experimentais de resistência à força cortante $\left(\mathrm{V}_{\text {Rexp }}\right)$ e valores teóricos característicos de resistência à força cortante $\left(\mathrm{V}_{\mathrm{RK}}\right)$ para lajes com alvéolos preenchidos após a liberação da protensão na pista de concretagem.

Tabela 2: Valores teóricos característicos $\left(\mathrm{V}_{\mathrm{RK}}\right)$ e experimentais $\left(\mathrm{V}_{\mathrm{Rexp}}\right)$ de resistência ao esforço cortante para lajes com preenchimento em obra - após a liberação da protensão da pista de concretagem.

\begin{tabular}{c|c|c|c|c|c|c|c|c|c|c}
\hline Modelo & $\begin{array}{c}\mathrm{N} .^{\circ} \mathrm{de} \\
\text { alvéolos } \\
\text { preench. }\end{array}$ & $\begin{array}{c}\text { Local de } \\
\text { preench. }\end{array}$ & $\begin{array}{c}\mathrm{f}_{\text {ck-laje }} \\
(\mathrm{MPa})\end{array}$ & $\begin{array}{c}\mathrm{f}_{\text {ck-alv. }} \\
(\mathrm{MPa})\end{array}$ & $\begin{array}{c}\mathrm{E} \\
(\mathrm{GPa})\end{array}$ & $\begin{array}{c}\mathrm{V}_{\mathrm{c}} \\
(\mathrm{kN})\end{array}$ & $\begin{array}{c}\mathrm{V}_{\mathrm{p}} \\
(\mathrm{kN})\end{array}$ & $\mathrm{V}_{\mathrm{c}} / \mathrm{V}_{\mathrm{p}}$ & $\begin{array}{c}\mathrm{V}_{\mathrm{RK}} \\
(\mathrm{kN})\end{array}$ & $\begin{array}{c}\mathrm{V}_{\text {Rexp }} \\
(\mathrm{kN})\end{array}$ \\
\hline $\mathrm{L}_{1}-\mathrm{A}_{0}$ & 0 & 0 & 56,83 & 0 & 30,86 & 107,22 & 53,90 & 1,99 & 161,12 & 198,9 \\
\hline $\mathrm{L}_{3}-\mathrm{O}_{35}-\mathrm{A}_{2}$ & 2 & obra & 56,83 & 33,75 & 19,52 & 180,51 & 75,34 & 2,40 & 255,85 & 197,9 \\
\hline $\mathrm{L}_{5}-\mathrm{O}_{45}-\mathrm{A}_{2}$ & 2 & obra & 56,83 & 38,88 & 17,41 & 172,59 & 71,11 & 2,43 & 243,69 & 196,4 \\
\hline $\mathrm{L}_{7}-\mathrm{O}_{35}-\mathrm{A}_{4}$ & 4 & obra & 56,83 & 33,75 & 19,52 & 180,51 & 53,90 & 3,35 & 234,40 & 196,4 \\
\hline $\mathrm{L}_{9}-\mathrm{O}_{45}-\mathrm{A}_{4}$ & 4 & obra & 56,83 & 38,88 & 17,41 & 172,59 & 53,90 & 3,20 & 226,48 & 212,4 \\
\hline
\end{tabular}

Sendo:

- $\mathrm{f}_{\text {ck-laje }}$ e $f_{\text {ck-alv. }}$ as resistências características à compressão do concreto da laje e do preenchimento, respectivamente;

- $\mathrm{V}_{\mathrm{c}}$ e $\mathrm{V}_{\mathrm{p}}$ a parcela de contribuição do concreto e da protensão na resistência ao esforço cortante, respectivamente;

- E os valores dos módulos de elasticidade dos concretos da laje e do preenchimento (35 e 45 MPa respectivamente) obtidos por meio de ensaio.

Com os resultados da resistência à força cortante das lajes, foi possível traçar um comparativo entre valores de cálculo e experimentais, sendo possível ainda avaliar a diferença entre os modelos com e sem preenchimento, bem como os instantes de preenchimento de alvéolos (antes da liberação e após a liberação da 
protensão da pista de concretagem), conforme a Figura 9.
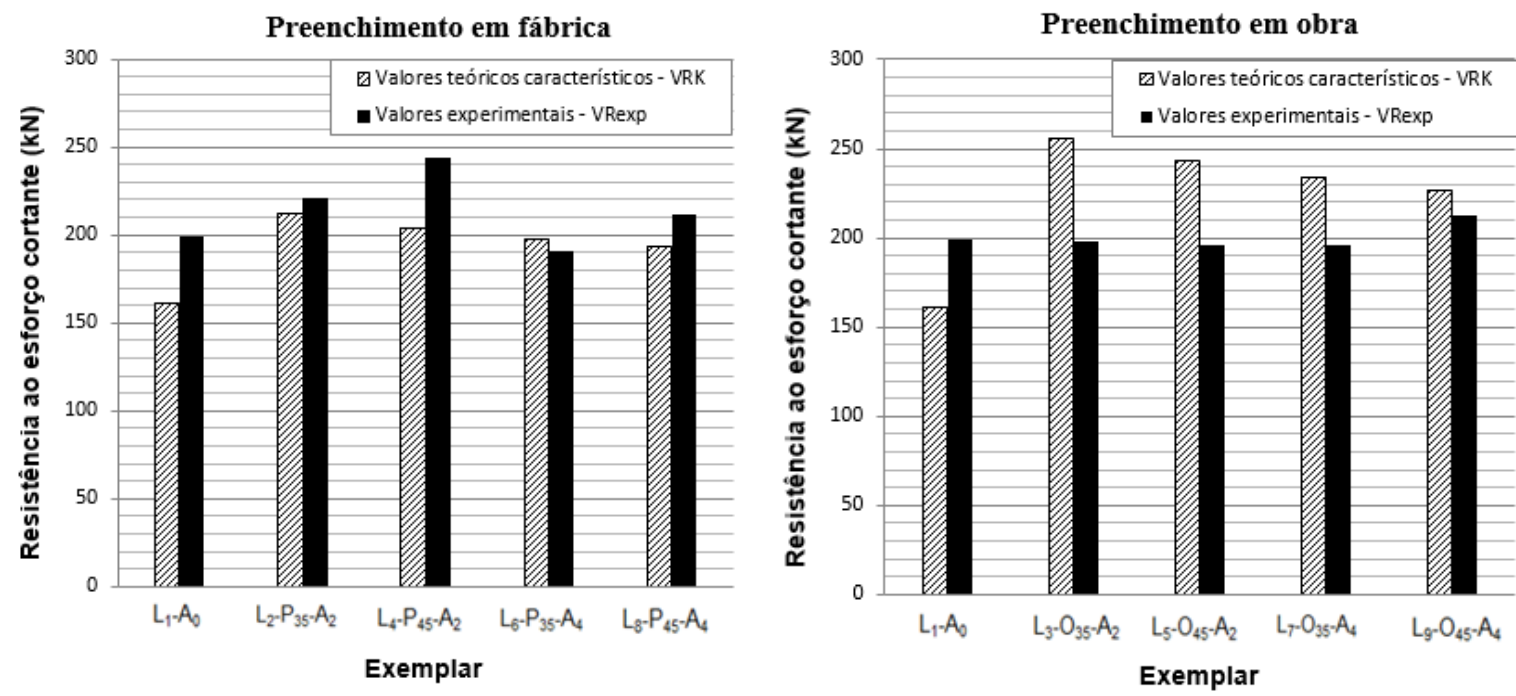

Figura 9: Comparação entre valores teóricos característicos e experimentais de resistência ao esforço cortante para lajes com alvéolos preenchidos antes e após a liberação da protensão na pista de concretagem respectivamente.

Nota-se que as lajes com alvéolos preenchidos antes da liberação da protensão na pista de concretagem, excluindo-se o modelo 6, apresentaram valores de resistência à força cortante $\left(\mathrm{V}_{\mathrm{Rexp}}\right)$ superiores aos valores teóricos característicos $\left(\mathrm{V}_{\mathrm{RK}}\right)$ obtidos através das formulações disponíveis na $\mathrm{ABNT}$ NBR 14861 [3], indicando que as formulações normativas atuais convergem para valores a favor da segurança para esta situação.

Observa-se que as formulações da norma apontam valores teóricos $\left(\mathrm{V}_{\mathrm{RK}}\right)$ de resistência à força cortante superiores quando o preenchimento de alvéolos é realizado após a liberação da protensão da pista de concretagem, quando comparados a lajes com preenchimento realizado antes da liberação da pista. Contudo, os valores experimentais $\left(\mathrm{V}_{\text {Rexp. }}\right)$ mostram que as lajes com preenchimento em fábrica possuem maior resistência ao esforço corante quando comparadas com as lajes que tiveram o preenchimento realizado em obra. Tal fato pode ser decorrente da retração e/ou falha na aderência entre o preenchimento e a laje, tendo em vista que o processo de preenchimento em fábrica é executado imediatamente após a extrusão do elemento, favorecendo assim a aderência entre a laje e o concreto de preenchimento.

Para as lajes com preenchimento em obra, o processo pode levar horas ou até dias, fazendo com que o material de preenchimento seja lançado sobre uma superfície de concreto já em seu estado endurecido e muitas vezes com uma ponte de aderência deficiente, que desfavorece a ligação entre os materiais.

Em ambas as situações de preenchimento, fábrica e obra, os ensaios apontam que ao se aumentar a resistência do material de preenchimento observa-se que a resistência ao esforço cortante tente a se manter ou aumentar, todavia, os valores teóricos apontam um decréscimo da resistência ao esforço cortante ao se aumentar a resistência à compressão do preenchimento.

Tanto valores teóricos quanto experimentais apontam para uma diminuição da resistência ao esforço cortante quando se aumenta o número de alvéolos preenchidos de 2 para 4.

O estudo teórico aponta um aumento de resistência de até $23,45 \%$ ao se realizar o preenchimento de alvéolos. Os dados experimentais mostram que para lajes com prenchimento em fábrica há um aumento, porém para elementos com preenchimento em obra apenas um modelo apresentou ganho, mostrando a influência do instante de preenchimento.

Em seu estudo, com lajes de $26,5 \mathrm{~cm}$ e dois ou três alvéolos preenchidos, FRANÇA [15] obteve um ganho de resistência ao esforço cortante de até $57,29 \%$ ao preencher dois alvéolos. Assim como apresentado pelo pesquisador [15], este estudo aponta casos onde lajes com um número maior de alvéolos preenchidos conduzem a um valor experimental de resistência ao esforço cortante inferior ao de lajes com um número menor de alvéolos preenchidos.

De modo análogo na pesquisa desenvolvida por CATOIA [7] com lajes de $20 \mathrm{~cm}$, elementos com 4 
alvéolos preenchidos apresentaram uma resistência ao esforço cortante de até 9,92\% inferior a lajes com 2 alvéolos preenchidos.

Tanto esta pesquisa quanto a literatura apresentam dispersão nos resultados, podendo ser consequência do número de variáveis envolvidas no processo de produção, preenchimento de alvéolos e ensaio das lajes. Atualmente a norma nacional[3] recomenda um fator de cálculo que faz com que a contribuição da parcela referente ao preenchimento de alvéolos seja reduzida a $50 \%$, desse modo as incertezas e variações seriam cobertas e valores seguros de resistência ao esforço cortante de lajes com preenchimento de alvéolos aplicados.

\section{CONCLUSÕES}

O presente estudo pretende contribuir para que a ABNT NBR 14861 [3] adquira maiores informações com relação ao ganho de resistência à força cortante de lajes alveolares com o preenchimento de 2 e 4 alvéolos, por meio do uso de preenchimento de alvéolos com concreto de mesma resistência à compressão ou superior, levando em consideração o instante do preenchimento (obra ou fábrica) e mecanismos de aderência entre o concreto da laje alveolar e o concreto de preenchimento.

Isso é de grande importância, pois os valores teóricos característicos divergem dos valores experimentais em uma parte considerável dos exemplares estudados. Além disso, na literatura técnica nacional, resultados de trabalhos de outros pesquisadores também mostram divergência entre valores teóricos e experimentais quanto a real influência do preenchimento de dois alvéolos. Os trabalhos existentes não apontam o melhor momento de execução do preenchimento, de acordo com esta pesquisa há influência do instante de preenchimento nos resultados dos ensaios.

Ao comparar os instantes de preenchimento, os resultados conduziram a valores superiores de capacidade resistente à força cortante quando o preenchimento de alvéolos é realizado após a liberação da protensão, já o estudo experimental aponta valores superiores de resistência quando o procedimento é realizado antes da liberação da protensão. Dados teóricos apontaram para uma diminuição da resistência ao esforço cortante ao se aumentar a resistência do concreto de preenchimento e também ao se preencher um maior número de alvéolos, não sendo esse fato observado em todos os modelos estudados.

Esses dados indicam uma necessidade de maiores investigações e possíveis ajustes na formulação atualmente empregada pela ABNT NBR 14861 [3] para o cálculo da resistência ao esforço cortante.

\section{AGRADECIMENTOS}

À Coordenação de Aperfeiçoamento de Pessoal de Nível Superior (CAPES), à Cassol Pré-fabricados Ldta, ao Programa de pós-graduação em Estruturas e Construção Civil (PPGECIV) da Universidade Federal de São Carlos (UFSCar).

\section{BIBLIOGRAFIA}

[1] ANTUNES, C. F. M., Resistência ao cisalhamento de lajes alveolares preenchidas: uma análise exploratória, dissertação de M.Sc., Departamento de Engenharia Civil, Universidade Federal de Goiás, Goiânia, 2011.

[2] ASSOCIAÇÃO BRASILEIRA DE NORMAS TÉCNICAS. NBR 9062 Projeto e Execução de Estruturas de Concreto Pré-Moldado, Rio de Janeiro, 2005.

[3] ASSOCIAÇÃO BRASILEIRA DE NORMAS TÉCNICAS. NBR 14861 Laje pré-fabricada-Painel alveolar de concreto protendido - Requisitos, Rio de Janeiro, 2011.

[4] ASSOCIAÇÃO BRASILEIRA DE NORMAS TÉCNICAS - NBR 6118 - Projeto de Estruturas de Concreto - Procedimento, Rio de Janeiro, 2014.

[5] ASSOCIATION OF MANUFACTURERS OF PRESTRESSED HOLLOW CORE FLOORS, ASSAP, The hollow core floor - Design and applications, Verona, Italy, 2002.

[6] CARVALHO, R. C.; FIGUEIREDO FILHO, J. R., Cálculo e detalhamento de estruturas usuais de concreto armado: segundo a NBR 6118:2003, 3.ed., São Carlos, EdUFSCar, 2007.

[7] CATOIA, B., Lajes Alveolares Protendidas: Cisalhamento em Região Fissurada por Flexão, Tese de D.Sc., Escola de Engenharia de São Carlos, Universidade de São Paulo, São Carlos 2011.

[8] CHENG, S., WANG, X., "Impact of interaction between adjacent webs on the shear strength of prestressed concrete hollow-core units", PCI Journal, v. 55, n. 3, pp. 46-63, Chicago, IL, Summer 2010 
[9] COSTA, O. O. Avaliação de desempenho de elementos de lajes alveolares protendidos pré-fabricados, Dissertação de M.Sc., Departamento de Engenharia Civil, Universidade Federal de São Carlos, São Carlos 2009.

[10] COMITÉ EUROPÉEN DE NORMALISATION, CEN. EN 1168:2005, Precast concrete products Hollow core slabs, (English version), Brussels, 2005.

[11] COMITÉ EUROPÉEN DE NORMALISATION, CEN. EN 1192:2004, Eurocode 2: Design of concrete structures - Part 1-1: General rules and rules for buildings. (English version), Brussels, 2004.

[12] EL DEBS, M.K., Concreto pré-moldado: Fundamentos e aplicações, 1 ed., São Carlos, EESC-USP, 2000.

[13] ELLIOTT, K. S., Precast Concrete Structures, 2 ed., London, England, Elsevier, 2002.

[14] FEDERATION INTERNATIONALE de la PRÉCONTAINTE, FIP, Guide to good practice: quality assurance of Hollow core slabs, London, England, 1992

[15] FRANÇA, A. A. V., Estudo Das Lajes Alveolares Pré-Fabricadas Em Concreto Protendido Submetidas A Ensaios De Cisalhamento, Dissertação de M.Sc., Setor de Tecnologia, Universidade Federal do Paraná, Curitiba.2012.

[16] FERREIRA, M.A., Manual de sistemas pré-fabricados de concreto (tradução). Autor do texto original: Arnold Van Acker (FIP-2002). Associação Brasileira da Construção Industrializada de Concreto - ABCIC, São Paulo, 2003.

[17] PALMER, K.D., SCHULTZ, A.E., Factors affecting web-shear capacity of deep hollow-core units, PCI Journal, v. 55, n. 2, pp. 123-146, Chicago, IL, Spring 2010.

[18] PINHEIRO, G. L., Estudo da influência do preenchimento de alvéolos em lajes alveolares submetidas à força cortante, Dissertação M.Sc., Departamento de Engenharia Civil, Universidade Federal de São Carlos, São Carlos, 2014.

[19] PRECAST/PRESTRESSED CONCRETE INSTITUTE (PCI), Manual for the design of hollow core slabs, 2 ed., chapter 1, Chicago, Illinois, 1998.

[20] STANTON, J.F., Response of hollow-core slab floors to concentrated loads. PCI journal, July-August 1992. PCI Journal, v. 37, n. 4, pp. 98-113, Chicago, IL, July-August 1992. 